\title{
Biodiesel Production Using Supercritical Methanol with Carbon Dioxide and Acetic Acid
}

\author{
Chao-Yi Wei, Tzou-Chi Huang, and Ho-Hsien Chen \\ Department of Food Science, National Pingtung University of Science and Technology, Neipu, Pingtung 91201, Taiwan
}

Correspondence should be addressed to Ho-Hsien Chen; hhchen@mail.npust.edu.tw

Received 29 September 2012; Revised 11 December 2012; Accepted 17 December 2012

Academic Editor: Ahmed A. Mohamed

Copyright (C) 2013 Chao-Yi Wei et al. This is an open access article distributed under the Creative Commons Attribution License, which permits unrestricted use, distribution, and reproduction in any medium, provided the original work is properly cited.

Transesterification of oils and lipids in supercritical methanol is commonly carried out in the absence of a catalyst. In this work, supercritical methanol, carbon dioxide, and acetic acid were used to produce biodiesel from soybean oil. Supercritical carbon dioxide was added to reduce the reaction temperature and increase the fats dissolved in the reaction medium. Acetic acid was added to reduce the glycerol byproduct and increase the hydrolysis of fatty acids. The Taguchi method was used to identify optimal conditions in the biodiesel production process. With an optimal reaction temperature of $280^{\circ} \mathrm{C}$, a methanol-to-oil ratio of 60 , and an acetic acid-to-oil ratio of 3, a 97.83\% yield of fatty acid methyl esters (FAMEs) was observed after 90 min at a reaction pressure of $20 \mathrm{MPa}$. While the common approach to biodiesel production results in a glycerol byproduct of about $10 \%$ of the yield, the practices reported in this research can reduce the glycerol byproduct by $30.2 \%$ and thereby meet international standards requiring a FAME content of $>96 \%$.

\section{Introduction}

Due to higher energy demands, more problems are associated with the widespread use of fossil fuels, recent rises in petroleum prices, and other energy concerns; it is increasingly necessary to develop renewable energy sources with smaller environmental impacts. In recent years, there have been increased demands for biodiesel, which is used as fuel in diesel engine systems. Generally, biodiesel is a mixture of fatty acid methyl esters (FAMEs), which may be derived from a variety of oils, fats, and waste oils and has similar physicochemical properties to conventional diesel [1-3]. Hence, biodiesel is compatible with existing diesel engines and can be utilized without major engine modifications. In addition, biodiesel combustion decreases emissions of $\mathrm{CO}_{2}, \mathrm{SO}_{x}$, and unburned hydrocarbons. Biodiesel obtained from energy crops favorably affects the environment and can help develop new industries, such as the agroenergy industry, which create employment and boost regional development. For these reasons, this renewable and environmentally friendly biofuel has the potential to ensure the sustainability of energy sources in the future by replacing exhaustible fossil fuels as the main energy supply. Despite the enormous benefits of biodiesel, high processing costs and expensive feedstock have acted as barriers to its development [4].

Transesterification of oils and lipids into biodiesel consists of replacing the glycerol of triglycerides with a shortchain alcohol, which can be achieved using various processes. Transesterification reactions can be catalyzed using alkaline, acidic, enzymatic, or other kinds of catalysts [5]. Most commonly, biodiesel production utilizes an alkaline catalyst, but it is difficult to adapt this process for use with some waste oils and fats. Enzymatic catalysis takes a long time to completely convert oils and fats into FAMEs. Biodiesel fuels can also be processed from oils via noncatalytic transesterification with supercritical alcohol [6], a process developed to resolve various problems. Such supercritical treatment can significantly reduce the reaction time, and the properties of the product mixture were found to fulfill international standards as well [7]. The raw material of oils or fats with high contents of free fatty acids can also be converted to FAMEs by an esterification reaction in supercritical methanol $[7,8]$. With this process, a high yield of FAMEs can be obtained, and there are no alkaline soaps generated. Moreover, separation 
and purification of the products are easy $[9,10]$. Unlike the alkali-catalyzed method, this method can also be applied to relatively long-chain alcohols.

The production of glycerol as a byproduct, however, has not been avoided (1), and with the increased production of biodiesel in years to come, a glut of glycerol may result. A method for producing biodiesel without producing glycerol, therefore, may prove efficacious. Ilham and Saka [11] proposed that dimethyl carbonate be used for noncatalytic, supercritical treatment in biodiesel production. Subsequently, Saka and Isayama [12] carried out a process utilizing noncatalytic, supercritical methyl acetate to produce a mixture of FAMEs and triacetylglycerol, commonly known as triacetin, without producing glycerol $[12,13]$. Hence, producing a mixture of FAMEs and triacetin has proven feasible, at least in cold climates and at high production costs. Such processes, which convert the glycerol byproduct into useful biodiesel additives, not only solve the problem of a glycerol glut in the market but also have the potential to improve the properties of the biodiesel produced. For instance, methyl acetate was proven to enhance biodiesel properties such as viscosity, flash point, and oxidation stability. Triacetin was also shown to be a valuable antiknock additive [14].

Saka et al. [15] also proposed a two-step process for converting oils and fats to fatty acids and triacetin using subcritical acetic acid followed by the conversion of fatty acids to FAMEs using supercritical methanol. We believe that methyl acetate can be produced from methanol and acetic acid (2). Methanol and $\mathrm{CO}_{2}$ may be catalyzed to form dimethyl carbonate (3) [16]. Hence, from an economic point of view, the simultaneous production of FAMEs and triacetin in a one-step reaction is a promising prospect [17].

In short, this ideal scenario improves the quality of biodiesel and minimizes the cost of processing biodiesel additives. This reaction is made possible by the transesterification of triglycerides and methyl acetate to produce FAMEs with triacetin as the byproduct instead of glycerol.

In this work, glycerol was subjected to esterification with acetic acid to produce a mixture of acetylglycerols (monoacetin, diacetin, and triacetin) as part of the production of biodiesel (4). We hope, therefore, to reduce the byproduct glycerol produced in biodiesel production and to improve the feasibility of biodiesel production in light of the processing technology and availability of raw materials, thus contributing to the development of this valuable and renewable energy resource

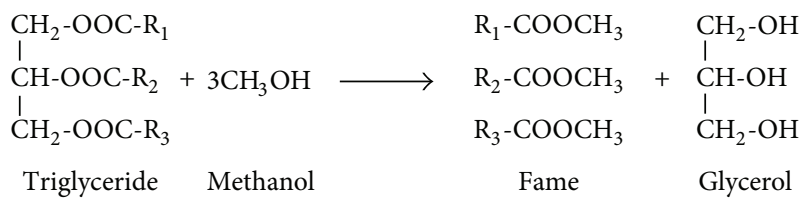

$$
\begin{aligned}
& \mathrm{CH}_{3} \mathrm{OH}+\mathrm{CH}_{3} \mathrm{COOH} \\
& \text { Methanol }
\end{aligned} \text { Acetic acid } \longrightarrow \begin{gathered}
\mathrm{CH}_{3} \mathrm{COOCH}_{3}+\mathrm{H}_{2} \mathrm{O} \\
\text { Methyl acetate }
\end{gathered}
$$
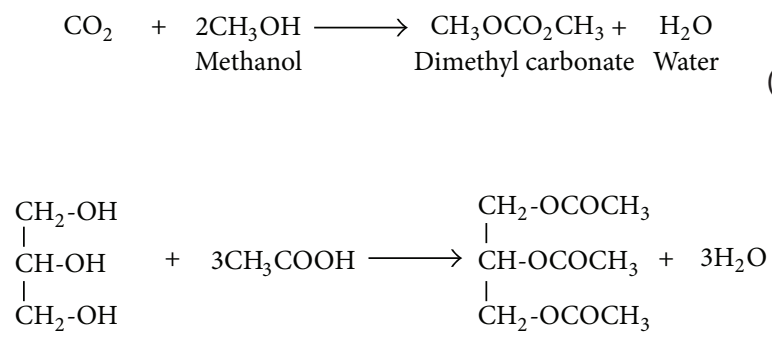

Glycerol Acetic acid Acetylglycerols Water

\section{Materials and Methods}

2.1. Experimental Planning. This experimental research plan was carried out using the Taguchi design method and an analysis of variance (ANOVA). The Taguchi method [18] systematically applies design and analysis principles to experiments, allowing the use of smaller amounts of experimental data to effectively identify improvements in the production process. This method can be employed in most kinds of industries to design processes and improve product quality with decreased costs, thereby economically optimizing manufacturing processes which may involve multiple factors at different levels. In the Taguchi method, orthogonal arrays are used to reduce the parameter numbers of the experimental trials to a practical yet effective level. Where a great number of independent variables are involved in the design of an experiment, the Taguchi method allows for more-sophisticated analyses of such variables with a smaller number of experiments.

The signal-to-noise ratio $(\mathrm{S} / \mathrm{N}$ ratio, $\eta)$ is a ratio of the average and standard deviation calculated from the experimental data. The $\mathrm{S} / \mathrm{N}$ ratio is the way the Taguchi method statistically measures the quality of production. The $\mathrm{S} / \mathrm{N}$ ratio equation depends on the criterion of the three quality characteristics to be optimized: higher-the-better, normalthe-better, and smaller-the-better. In this research on the production of biodiesel with higher FAMEs and less glycerol, the $\mathrm{S} / \mathrm{N}$ ratio of the methyl ester concentration in biodiesel (the higher-the-better function) was used as follows (5):

$$
\eta=-10 \times \log \left(\frac{1}{n} \sum_{i=1}^{n} \frac{1}{y_{i}^{2}}\right)(d b),
$$

where $y_{i}$ is the $i$ th quality parameter and $n$ is the number of trials.

A number of independent variables are involved in the production of biodiesel from soybean oil, including the reaction temperature, reaction time, molar ratio of methanol/oil, and molar ratio of acetic acid/oil. Taguchi L9 designs and Taguchi $3^{4}$ partial fractional factorial designs were used, including standard Taguchi L9 orthogonal arrays requiring nine experiments (Table 1). In this study, the influences of four variables (reaction time, reaction temperature, molar ratio of methanol/oil, and molar ratio of acetic acid/oil) on glycerol contents were investigated. The experimental error was determined by conducting two replicate experiments with detailed statistical analyses of the results. The levels 
TABLE 1: Experimental plan by the L9 Taguchi design applied to biodiesel production.

\begin{tabular}{lcccc}
\hline L9 & \multicolumn{4}{c}{ Factors } \\
& $A$ & $B$ & $C$ & $D$ \\
Run & Temp. & Time & Methanol/oil & Acetic acid/oil \\
\hline 1 & -1 & -1 & -1 & -1 \\
2 & -1 & 0 & 0 & 0 \\
3 & -1 & +1 & +1 & +1 \\
4 & 0 & -1 & 0 & +1 \\
5 & 0 & 0 & +1 & -1 \\
6 & 0 & +1 & -1 & 0 \\
7 & +1 & -1 & +1 & 0 \\
8 & +1 & 0 & -1 & +1 \\
9 & +1 & +1 & 0 & -1 \\
\hline
\end{tabular}

TABLE 2: Levels of variables in biodiesel production.

\begin{tabular}{lcccc}
\hline \multirow{2}{*}{ Factors } & \multirow{2}{*}{ Parameter } & \multicolumn{3}{c}{ Levels and values } \\
& & Low $(-1)$ & Medium (0) & High (1) \\
\hline$A$ & Temperature $\left({ }^{\circ} \mathrm{C}\right)$ & 260 & 280 & 300 \\
$B$ & Time (min) & 30 & 60 & 90 \\
$C$ & Methanol/oil & 20 & 40 & 60 \\
$D$ & Acetic acid/oil & 1 & 2 & 3 \\
\hline
\end{tabular}

(A: temperature; $B$ : time; $C$ : molar ratio (methanol/oil); $D$ : molar ratio (acetic acid/oil)).

and values of all variables applied in the experiments are presented in Table 2.

2.2. System Set-Up. Soybean oil bought from a market (Taisugar, Kaohsiung, Taiwan) was used in this research. Samples were converted to methyl esters by noncatalytic transesterification in a supercritical fluid system (Lian-Sheng, Taichung, Taiwan). All runs of the experiment were performed in a $150 \mathrm{~mL}$ cylindrical autoclave made of stainless steel (no. 316) as shown in Figure 1.

The sample was loaded into the autoclave by a highpressure pump for each run. In a typical run, the autoclave was charged with a given amount of soybean oil $(30 \mathrm{~mL})$ and liquid methanol $(20 \sim 80 \mathrm{~mL})$ (Nihon Shiyaku Industries, Osaka, Japan) with variable molar ratios. The reaction tank was heated with an electrical heater, and power was adjusted to give reaction temperatures of 260 $300^{\circ} \mathrm{C}$ and reaction times of $30-90 \mathrm{~min}$. The system was pressurized with carbon dioxide (20 MPa) (Jing-Shang Gas, Kaoushiung, Taiwan). After completion of the reaction, the high-pressure valve was opened to stop the reaction and separate the products from the reactor. Solvents of control groups used to replace supercritical Methanol were methyl acetate (Panreac, Barcelona, Spain) $50 \mathrm{~mL}$ and dimethyl carbonate (Alfa Aesar, MA, USA) $55 \mathrm{~mL}$, respectively. Without adding acetic acid, only $30 \mathrm{~mL}$ of soybean oil was added. It was pressurized to $20 \mathrm{MPa}$ at temperature $300^{\circ} \mathrm{C}$ with carbon dioxide, and reaction time was maintained up to $60 \mathrm{~min}$.

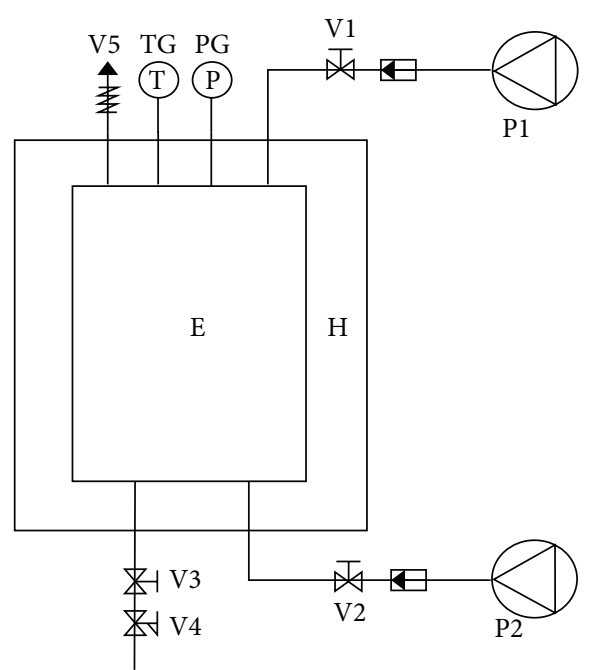

FIgURE 1: Schematic diagram of the supercritical reaction system: $\mathrm{E}$, reaction vessel; $\mathrm{H}$, heater and jacket; $\mathrm{P} 1$, high-pressure liquid pump; P2, super-critical $\mathrm{CO}_{2}$ pump; V1 3, high-pressure valves; V4, back-pressure valve; V5, release valve; PG, pressure gauge; TG, temperature gauge.

2.3. Conversion of FAME. FAME concentrations of each sample were analyzed (modified from ISO5508) by a gas chromatographic (GC) system (Hewlett-Packard 5890 Packard Series II, Ramsey, MN, USA), equipped with a DB-wax capillary vessel column $(30 \mathrm{~m} \times 0.25 \mathrm{~mm}$ ID $\times 0.25 \mu \mathrm{m}$ film thickness of polyethylene glycol). The detector and injector temperatures were both set to $250^{\circ} \mathrm{C}$. The oven temperature was maintained at a constant $200^{\circ} \mathrm{C}$. Methyl heptadecanoate was obtained from Sigma-Aldrich (St. Louis, MO, USA) as an internal standard. All of the analytical assays were performed in duplicate, and mean values are presented. According to the GC integral data, the contraction of FAMEs was calculated by (6)

$$
C=\frac{(\Sigma A)-A_{E I}}{A_{E I}} \times \frac{C_{E I} \times V_{E I}}{m} \times 100 \%,
$$

where $\Sigma A$ is the peak integral area of C14 to C24:1 FAMEs, $A_{E I}$ is the peak area of the internal standard (heptadecanoic acid methyl ester; HAME), $C_{E I}$ is the concentration of HAME in the solution $(\mathrm{mg} / \mathrm{mL}), V_{E I}$ is the volume of HAME in the solution (mL), and $m$ is the sample weight (mg).

\section{Results and Discussion}

3.1. FAME Content. This study compared the supercritical methanol method of biodiesel production with two glycerolfree methods: the supercritical methyl acetate and supercritical dimethyl carbonate methods. Table 3 shows critical properties of various solvents. In this work, temperature $\left(300^{\circ} \mathrm{C}\right)$ and pressure $(20 \mathrm{MPa})$ were used, which were higher than those critical points in Table 3, to ensure that a supercritical medium was generated. Before the reaction, the methanol, soybean oil, and acetic acid divided clearly into three layers. The dimethyl carbonate and methyl acetate mixed very well 
TABLE 3: The critical properties of various solvents.

\begin{tabular}{lcc}
\hline Solvent & $\begin{array}{c}\text { Critical temperature } \\
\left({ }^{\circ} \mathrm{C}\right)\end{array}$ & $\begin{array}{c}\text { Critical pressure } \\
(\mathrm{MPa})\end{array}$ \\
\hline Carbon dioxide & 31.1 & 7.4 \\
Methanol & 239.6 & 8.1 \\
Methyl acetate & 233.7 & 4.6 \\
Dimethyl carbonate & 274.9 & 4.6 \\
\hline
\end{tabular}

with the soybean oil. We predicted that the contact area of reaction substrates would affect the reaction rate and yield. After completing the reaction and collecting samples, the glycerol and FAME contents were calculated individually. Figure 2 shows the peaks of the FAME analysis with an interstandard analysis by GC. Samples were obtained using different supercritical fluids in the same reaction situation as supercritical methanol (Run no. 8 in Table 4), using a run temperature of $300^{\circ} \mathrm{C}$, a reaction time of $60 \mathrm{~min}$, a pressure of $20 \mathrm{MPa}$, and a solvent-to-oil ratio of 20 . The results showed that using supercritical methanol with acetic acid produced biodiesel with a much better FAME content $(63.38 \%)$ than methods using supercritical methyl acetate $(3.41 \%)$ or supercritical dimethyl carbonate (13.77\%). This may have been due to an application of the international standard FAME analytical method to C14 to C24:1 FAMEs in the biodiesel samples. Producing biodiesel using the supercritical methyl acetate and supercritical dimethyl carbonate methods also results in the production of monoglycerol acetate, diglycerol acetate, and triglycerol acetate.

The FAME content, which was calculated with a known concentration of HAME $(10 \mathrm{mg} / \mathrm{mL})$ using (2), of each run of the experiment is shown in Table 4 . We studied the effects of individual experimental factors on the methyl ester content based on good quality (higher-the-better, (1)) and the calculation of the $\mathrm{S} / \mathrm{N}$ ratio of each of the experimental factors to determine a set of optimal conditions, as shown in Figure 3. An optimal biodiesel yield resulted with a temperature of $280^{\circ} \mathrm{C}$, a reaction time of $90 \mathrm{~min}$, a methanol-to-oil molar ratio of 60 , and an acetic acid-to-oil molar ratio of 3. After running a confirmation experiment, we obtained an optimal mean FAME content of $97.82 \%$.

ANOVA is a way to statistically authenticate how control factors and parameters affect results. Table 5 shows the ANOVA values for biodiesel production, demonstrating that each reaction factor significantly affected the glycerol and FAME concentrations in the biodiesel reaction system. Biodiesel samples produced were also tested by using them in a diesel generator, which ran smoothly and showed no differences in performance from regular diesel.

3.2. Effect of Reaction Temperature. We investigated the effects of the reaction temperature on the conversion of FAMEs. Results showed that the reaction temperature was the most significant factor affecting both the FAME and glycerol contents. The higher the temperature, the faster the reaction was completed and the more FAMEs that were produced. Higher reaction temperatures resulted in better solubility of the substrates and better molecular activity, which increased the relative probability of collisions and the reaction rate. An increase in the reaction temperature also allowed easier breaking of the bonds of triglycerides and methyl combinations into FAMEs. Too high a reaction temperature for too long a period, however, will break down the FAMEs that have formed and will increase heating costs.

Higher reaction temperatures, however, also produced higher glycerol contents. Thus, a balance between meeting international biodiesel standards and lowering the output of byproducts must be struck in the biodiesel production process.

3.3. Effect of Reaction Time. Increasing reaction times resulted in no significant increase in FAME content, suggesting that the biodiesel conversion reaction had reached homeostasis after a period of time, a result which was consistent with the reaction kinetics curve. In other words, the biodiesel conversion was already completed in a short time. An increased reaction time, however, did increase the glycerol content.

3.4. Effect of the Methanol-to-Oil Ratio. Results showed that a higher proportion of methanol to oil achieved a better concentration of FAMEs in the samples produced; as the proportion of methanol increased, the concentration of FAMEs generated also increased, because methanol acts as a reactant and also provides the main medium for the reaction system. Using more methanol achieved a higher reactant solubility in the reaction system, but samples collected contained a higher ratio of methanol. An additional process was required to recover it.

3.5. Effect of the Acetic Acid-to-Oil Ratio. The molar ratio of acetic acid to oil affected the FAME content; adding more acetic acid to the system produced a higher FAME content. Adding acetic acid also promoted the hydrolysis of triglycerides into fatty acids, which improved the conversion yield. At the same time, methanol and acetic acid reacted in the system to form methyl acetate, which then reacted with the glycerol byproduct to form triacetin and thereby lowered the glycerol content. Methyl acetate is also a cosolvent, which increased the solubility of substrates in the supercritical methanol system.

\section{Conclusions}

A method utilizing supercritical methanol to manufacture biodiesel resulted in higher FAME contents while avoiding higher glycerol contents. This method may assist in meeting international standards for biodiesel production while also lowering the production of byproducts. In this research, we added acetic acid to the FAME conversion system, and at the same time, methanol and acetic acid reacted to produce methyl acetate. The acetic acid promoted triglyceride hydrolysis into fatty acids and thereby enhanced the biodiesel conversion in supercritical methanol. The glycerol byproduct then reacted with the methyl acetate to form 
TABLE 4: Results of L9 $\left(3^{4}\right)$ orthogonal array experiments on fatty acid methyl ester (FAME) and glycerol contents of biodiesel production samples.

\begin{tabular}{lcccccccc}
\hline \multirow{2}{*}{ Run } & \multicolumn{3}{c}{ FAME content } & \multicolumn{3}{c}{ Glycerol content } \\
& Test 1 (\%) & Test 2 (\%) & AVG & SD & S/N ratio (db) & Test 1 (\%) & Test 2(\%) & AVG \\
\hline 1 & 35.73 & 38.22 & 38.22 & 3.51 & 31.59 & 3.21 & 3.67 & 3.44 \\
2 & 51.1 & 51.47 & 51.47 & 0.52 & 34.23 & 5.29 & 5.59 & 5.44 \\
3 & 61.12 & 60.44 & 60.44 & 0.97 & 35.62 & 5.27 & 5.52 & 5.39 \\
4 & 85.97 & 86.49 & 86.49 & 0.74 & 38.74 & 5.44 & 5.64 & 5.54 \\
5 & 85.17 & 82.35 & 82.35 & 4 & 38.3 & 5.63 & 6.08 & 5.85 \\
6 & 72.3 & 72.46 & 72.46 & 0.22 & 37.2 & 6.85 & 7.19 & 7.02 \\
7 & 85.27 & 82.73 & 82.73 & 3.59 & 38.34 & 6.01 & 6.39 & 6.2 \\
8 & 62.05 & 63.38 & 63.38 & 1.88 & 36.03 & 6.79 & 6.17 & 6.98 \\
9 & 71.88 & 70.45 & 70.45 & 2.03 & 36.95 & 6.63 & 6.01 & 6.82 \\
CT & 98.17 & 97.48 & 97.83 & 0.49 & 39.81 & 6.74 & 7.22 & 6.98 \\
\hline
\end{tabular}

AVG: average; SD: standard deviation; S/N: signal-to-noise ratio; CT: confirmation test.

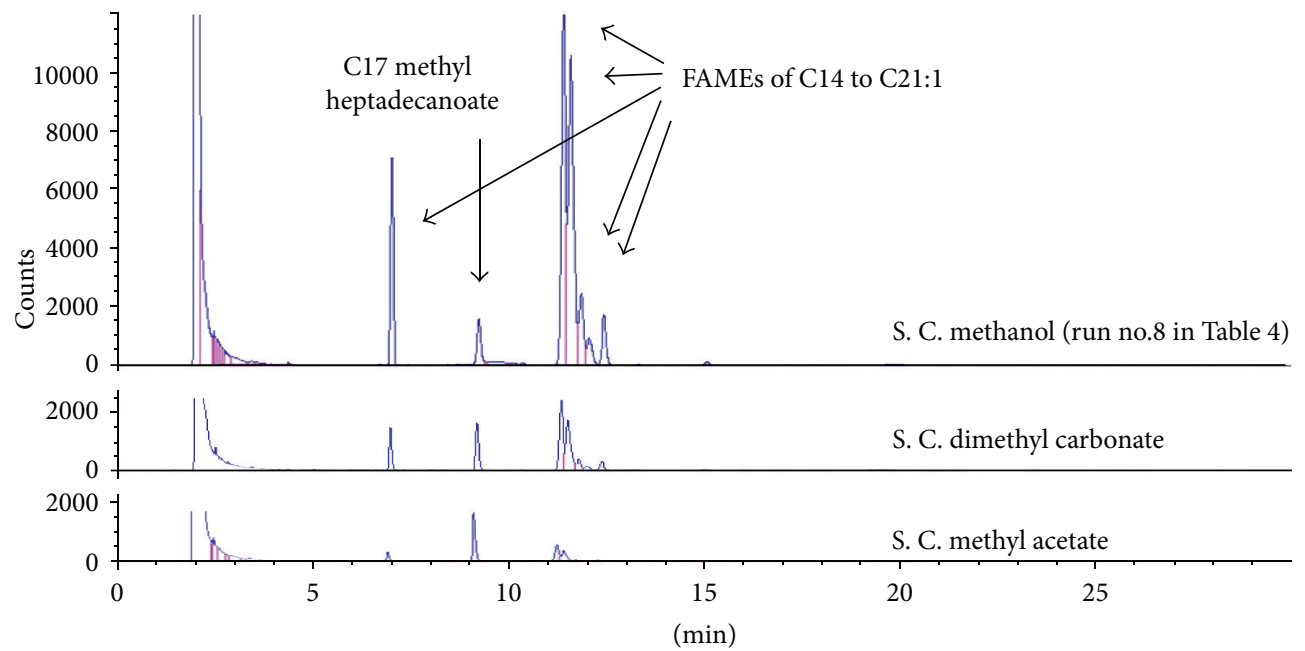

FIGURE 2: GC diagram of fatty acid methyl esters (FAMEs) with an internal standard (methyl heptadecanoate) prepared by supercritical fluid methods.

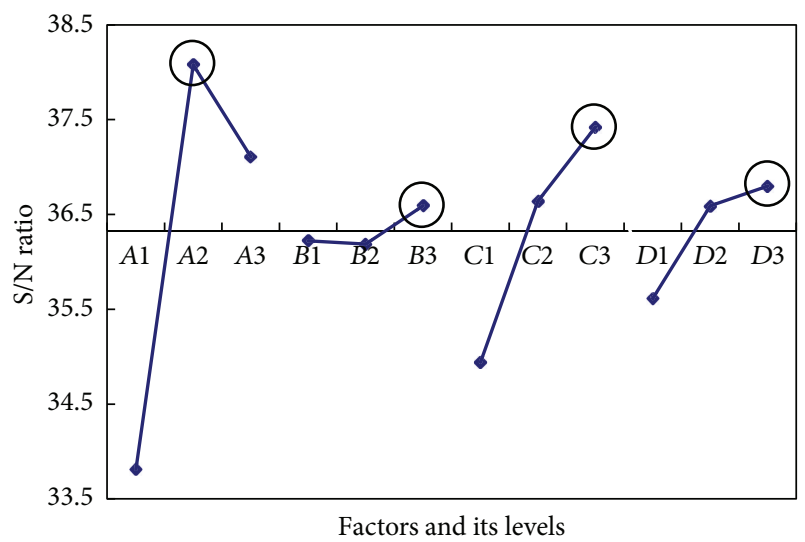

FIGURE 3: Response graph of higher-the-better signal-to-noise ratios for fatty acid methyl aster (FAME) contents at different conditions ( $A$, temperature; $B$, time; $C$, molar ratio (methanol/oil); $D$, molar ratio (acetic acid/oil)).
TABLE 5: Analysis of variance summary table of fatty acid methyl ester (FAME) concentrations.

\begin{tabular}{lccccc}
\hline & SS & DF & MS & $F$ & CF \\
\hline$A$ & 2964.22 & 2 & 1482.11 & 263.28 & 100.00 \\
$B$ & 35.45 & 2 & 17.73 & 3.15 & 90.81 \\
$C$ & 915.73 & 2 & 457.87 & 81.33 & 100.00 \\
$D$ & 140.14 & 2 & 70.07 & 12.45 & 99.74 \\
Error & 50.66 & 9 & 5.63 & & \\
\hline Total & 4106.20 & 17 & & & \\
\hline
\end{tabular}

( $A$ : temperature; $B$ : time; $C$ : molar ratio (methanol/oil); $D$ : molar ratio (acetic acid/oil)).

SS: sum of squares; DF: degrees of freedom; MS: mean square; $F: F$ ratio, CF: confidence.

triacetin, decreasing the glycerol content. Methyl acetate is also a co-solvent, which provides substrate solubility in the supercritical methanol system. In this research, an optimal 
reaction temperature of $280^{\circ} \mathrm{C}$, a methanol-to-oil ratio of 60 , and an acetic acid-to-oil ratio of 3 yielded a FAME content of $97.83 \%$ and a glycerol content of $6.98 \%$ after $90 \mathrm{~min}$ at a reaction pressure of $20 \mathrm{MPa}$. The current standard method for converting biodiesel using supercritical methanol produced about $10 \%$ glycerol. The method used in this study, therefore, decreased the production of the glycerol byproduct by about $30 \%$ and met the international standard for biodiesel requiring a FAME content exceeding 96\%.

\section{References}

[1] E. Alptekin and M. Canakci, "Optimization of transesterification for methyl ester production from chicken fat," Fuel, vol. 90, no. 8, pp. 2630-2638, 2011.

[2] A. Demirbas, "Biodiesel from waste cooking oil via basecatalytic and supercritical methanol transesterification," Energy Conversion and Management, vol. 50, no. 4, pp. 923-927, 2009.

[3] P. Vallea, A. Velezb, P. Hegelb, G. Mabeb, and E. A. Brignoleb, "Biodiesel production using supercritical alcohols with a nonedible vegetable oil in a batch reactor," Journal of Supercritical Fluids, vol. 54, pp. 61-70, 2010.

[4] A. Deshpande, G. Anitescu, P. A. Rice, and L. L. Tavlarides, "Supercritical biodiesel production and power cogeneration: technical and economic feasibilities," Bioresource Technology, vol. 101, no. 6, pp. 1834-1843, 2010.

[5] J. M. Marchetti, V. U. Miguel, and A. F. Errazu, "Possible methods for biodiesel production," Renewable and Sustainable Energy Reviews, vol. 11, no. 6, pp. 1300-1311, 2007.

[6] K. T. Tan, K. T. Lee, and A. R. Mohamed, "Effects of free fatty acids, water content and co-solvent on biodiesel production by supercritical methanol reaction," Journal of Supercritical Fluids, vol. 53, no. 1-3, pp. 88-91, 2010.

[7] K. T. Tan, K. T. Lee, and A. R. Mohamed, "A glycerol-free process to produce biodiesel by supercritical methyl acetate technology: an optimization study via Response Surface Methodology," Bioresource Technology, vol. 101, no. 3, pp. 965-969, 2010.

[8] H. Imahara, E. Minami, S. Hari, and S. Saka, "Thermal stability of biodiesel in supercritical methanol," Fuel, vol. 87, no. 1, pp. $1-6,2008$.

[9] I. M. Atadashi, M. K. Aroua, and A. A. Aziz, "Biodiesel separation and purification: a review," Renewable Energy, vol. 36, no. 2, pp. 437-443, 2011.

[10] Y. Shimoyama, T. Abeta, L. Zhao, and Y. Iwai, "Measurement and calculation of vapor-liquid equilibria for methanol + glycerol and ethanol + glycerol systems at 493-573 K," Fluid Phase Equilibria, vol. 284, no. 1, pp. 64-69, 2009.

[11] Z. Ilham and S. Saka, "Dimethyl carbonate as potential reactant in non-catalytic biodiesel production by supercritical method," Bioresource Technology, vol. 100, no. 5, pp. 1793-1796, 2009.

[12] S. Saka and Y. Isayama, "A new process for catalyst-free production of biodiesel using supercritical methyl acetate," Fuel, vol. 88, no. 7, pp. 1307-1313, 2009.

[13] K. T. Tan, M. M. Gui, K. T. Lee, and A. R. Mohamed, "An optimized study of methanol and ethanol in supercritical alcohol technology for biodiesel production," Journal of Supercritical Fluids, vol. 53, no. 1-3, pp. 82-87, 2010.

[14] J. A. Melero, R. van Grieken, G. Morales, and M. Paniagua, "Acidic mesoporous silica for the acetylation of glycerol: synthesis of bioadditives to petrol fuel," Energy \& Fuels, vol. 21, no. 3, pp. 1782-1791, 2007.
[15] S. Saka, Y. Isayama, Z. Ilham, and X. Jiayu, "New process for catalyst-free biodiesel production using subcritical acetic acid and supercritical methanol," Fuel, vol. 89, no. 7, pp. 1442-1446, 2010.

[16] D. Ballivet-Tkatchenko, S. Chambrey, R. Keiski et al., "Direct synthesis of dimethyl carbonate with supercritical carbon dioxide: characterization of a key organotin oxide intermediate," Catalysis Today, vol. 115, no. 1-4, pp. 80-87, 2006.

[17] M. Fusayasu, T. Kamitanaka, T. Sunamura, T. Matsuda, T. Osawa, and T. Harada, "Transesterification of supercritical ethyl acetate by higher alcohol," Journal of Supercritical Fluids, vol. 54, no. 2, pp. 231-236, 2010.

[18] G. Taguchi, Introduction to Quality Engineering, Asian Productivity Organization, Tokyo, Japan, 1990. 

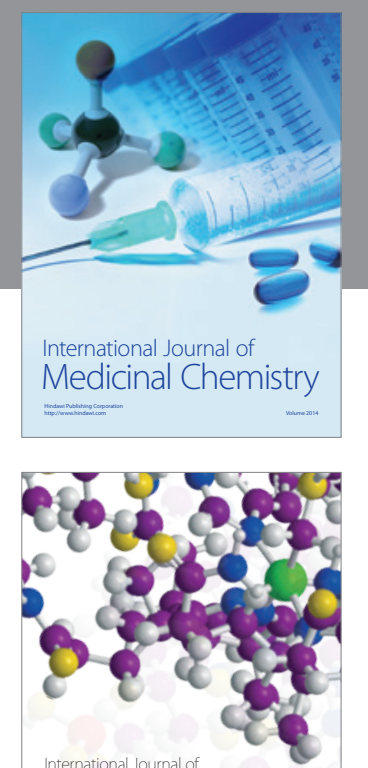

\section{Carbohydrate} Chemistry

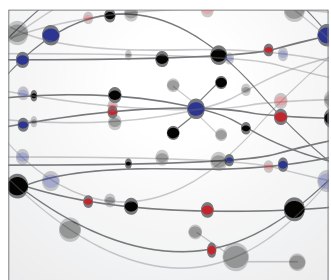

The Scientific World Journal
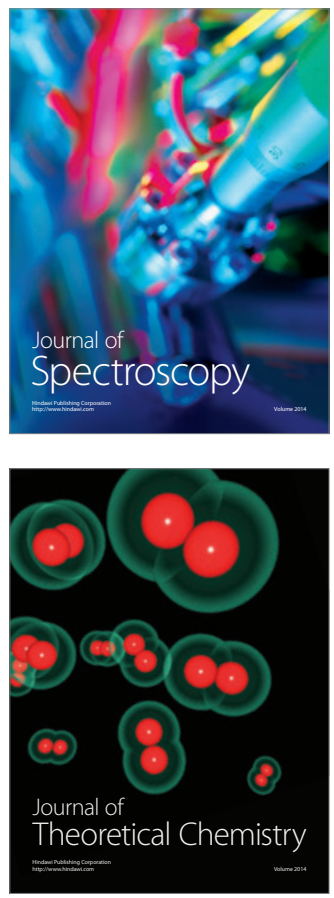
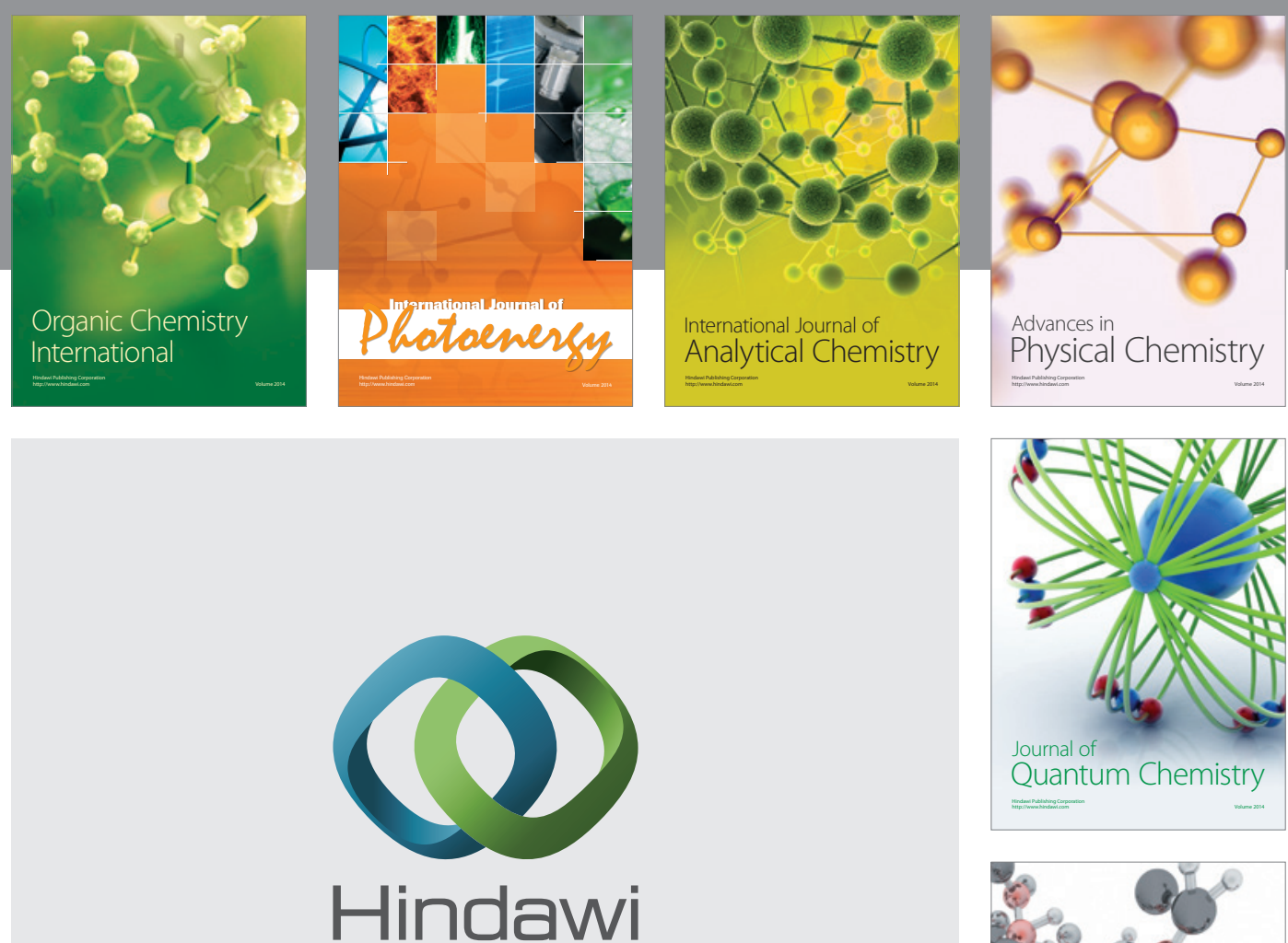

Submit your manuscripts at

http://www.hindawi.com

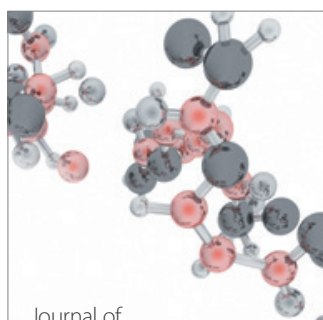

Analytical Methods

in Chemistry

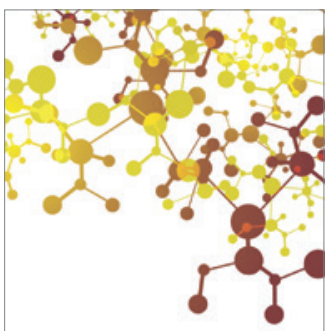

Journal of

Applied Chemistry

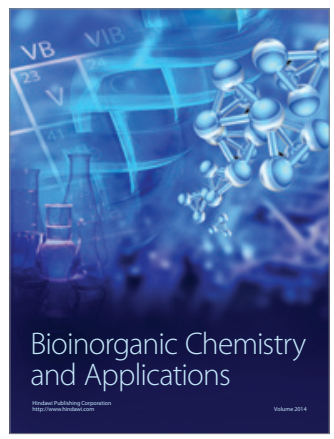

Inorganic Chemistry
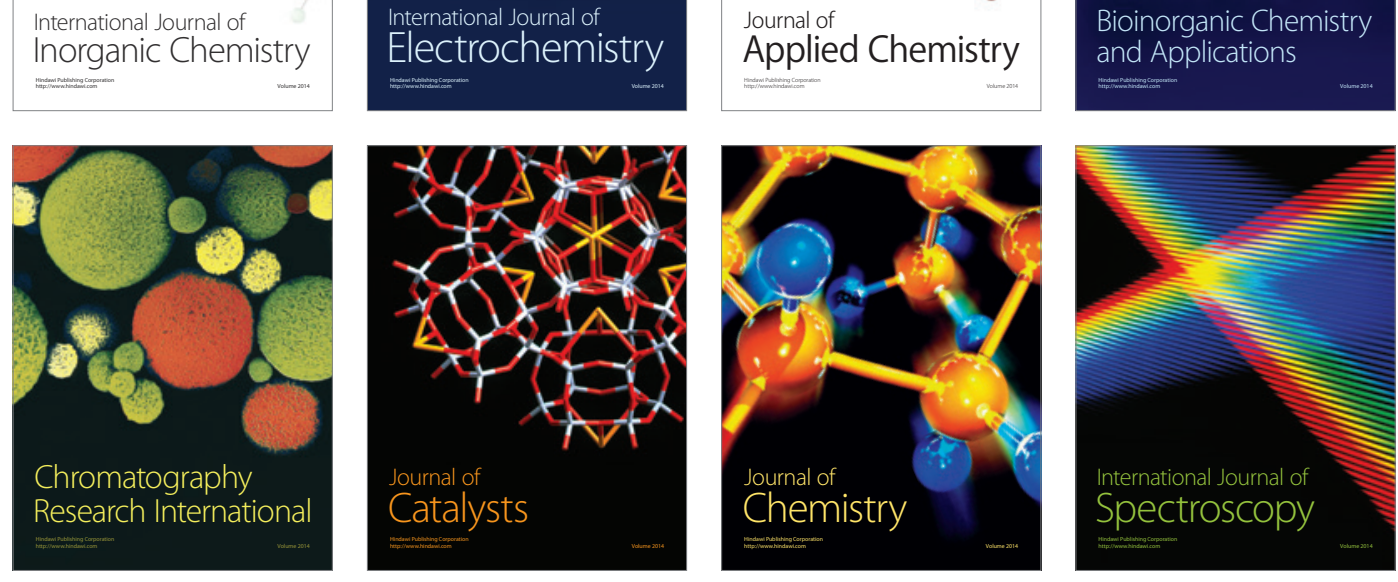